\title{
Primary Cardiac Tumours in Childhood
}

\author{
A. SIMCHA ${ }^{\star}$, B. G. WELLS, M. J. TYNAN, and D. J. WATERSTON
}

\begin{abstract}
Simcha, A., Wells, B. G., Tynan, M. J., and Waterston, D. J. (1971). Archives of Disease in Childhood, 46, 508. Primary cardiac tumours in childhood. Eight children with cardiac tumours are described. Six were diagnosed as spaceoccupying lesions after they had been investigated without incident; all six were operated upon and two survived. The need to investigate and treat these tumours surgically is emphasized.
\end{abstract}

The past decade has changed our approach towards primary cardiac tumours; from being a rarity found incidentally at necropsy, they now constitute a well-established entity, to be diagnosed clinically and treated surgically (Prichard, 1951; Gerbode, Kerth, and Hill, 1967). This change is due to better understanding of the clinical symptomatology of the tumours, to advances in diagnostic tools such as angiocardiography, and to the improvement in bypass techniques.

Primary cardiac tumours are exceedingly rare (Fine, 1968; Wood, 1968) particularly so in infancy and childhood (Van der Hauwaert, 1968; Nadas and Ellison, 1968), the literature in this age group consisting mainly of single case reports (James and Stanfield, 1955; Catton, Guntheroth and Reichenbach, 1963; Edlund and Holmdahl, 1957), and even centres specializing in congenital heart disease report only small series (Gasul, Arcilla and Lev, 1966; Keith, Rowe and Vlad, 1967).

During the past 20 years, 8 patients with primary cardiac tumours were seen at The Hospital for Sick Children, giving an incidence of approximately $0.08 \%$ of all cases of congenital heart disease seen at this hospital. Of these 8 patients, 4 had rhabdomyomas, 2 had fibromas, and 2 had myxomas. Only 2 of the tumours were found at necropsy (both in children with tuberous sclerosis), the rest were suspected or diagnosed clinically, and operated upon. The 2 surviving patients have been previously reported (Lincoln, Tynan, and Waterston, 1968.

In order to review the clinical and pathological manifestation of the tumours, we first summarize

Received 8 February 1971

* Morrison Foundation Fellow, Thoracic Unit, The Hospital for Sick Children, Great Ormond Street, London. the clinical features of the 8 patients, the order of presentation being given according to the pathological classification of the tumours (A) rhabdomyomas, (B) fibromas, (C) myxomas.

\section{Clinical Summaries}

A1: Female, 5 years 4 months. Born after uneventful pregnancy. Started with petit mal seizures at the age of 6 months but had normal development up to 1 year of age. At 18 months thought to be backward, since then deteriorated and developed grand $\mathrm{mal}$, and epileptic status. Skin manifestations of adenoma sebacaceum developed around the 3 rd year of life. No pathological findings in the heart were noticed, but the electrocardiogram showed paroxysmal atrial extrasystoles. Died suddenly at the age of 5 years 4 months, during an uncontrolled epileptic fit.

Necropsy showed the classical findings of tuberous sclerosis in the skin and brain, multiple cysts and tumours of the kidneys, and diffuse intramural tumours of the heart both in the right and left ventricles, rhabdomyatous in origin.

A2: Female, 4 years. This female child was mentally retarded and had epilepsy. The father had aminoaciduria and glucosuria, from which the patient suffered as well. Her twin sister had proven Fanconi type aminoaciduria with renal rickets. The patient was treated by anticonvulsant therapy, but was only partially controlled. Her last admission to the hospital was because of vomiting, dehydration, and uncontrolled convulsions. While having a generalized seizure she collapsed and had a cardiac arrest; after open cardiac massage, the heart started beating again. A tracheostomy was performed, she was ventilated, and later resumed spontaneous breathing. Five days later she died suddenly.

Necropsy showed extensive skin and brain changes characteristic of tuberous sclerosis, massive ischaemic changes in the brain, rhabdomyomata of the kidneys with cystic changes, nephrocalcinosis, and empyema of the left pleura-most probably as a result of the open 
massage. The heart showed diffuse intramural rhabdomyomas in the left and right ventricle.

A3: Female, 2 months. This female developed transient cyanosis a few hours after birth. One week later cyanosis was observed for the second time and persisted; at 2 weeks there was slow feeding and breathlessness. After digitalization there was some improvement, and at that stage she was referred to this hospital. On admission, she was not cyanosed, but had no respiratory distress. Full pulses were noted with an enlarged heart. A systolic murmur over the pulmonary artery and left sternal edge was present. The liver was $4 \mathrm{~cm}$ below the costal margin. ECG showed marked right ventricular hypertrophy with digitalis effect. On chest $x$-ray the heart was enlarged, and the lung vascularity was diminished. Cardiac catheterization was performed but repeated attempts to enter the pulmonary artery were unsuccessful. The RV pressure was raised $80 / 1 \mathrm{mmHg}$, and a left-to-right shunt at atrial level was detected. Right ventricular angiogram showed a filling defect in the pulmonary outflow tract proximal to the valve, and a second filling defect arising from the ventricular septum was shown as well. The baby was operated upon with the aid of cardiopulmonary bypass. A large tumour was found originating from the right ventricle and protruding into the pulmonary artery, causing severe outflow obstruction. During the ventriculotomy there was cardiac arrest, the mass occluding the pulmonary outflow tract was rapidly removed, and vigorous resuscitative measures were instituted, but the heart did not respond.

Necropsy showed tuberous sclerosis changes over the cerebral hemispheres, and lesions of hamartomatous nature in the left kidney.

In the heart multiple tumours were found in the right ventricle, and these were histologically rhabdomyomas.

A4: Female, 3 weeks. Cyanosed from birth, this baby fed well and did not appear to be in distress. She had a very large heart with palpable pulsation over the left sternal edge, short soft systolic ejection murmur over the pulmonary area, and a widely split pulmonary second sound. ECG showed wandering pacemaker with left bundle-branch block (Wolff-Parkinson-White syndrome could not be excluded). Chest $x$-ray showed a very large heart.

Cardiac catheterization was done at the age of 22 days. The pulmonary artery could not be entered. The pressure in the right ventricle was raised to $80 / 8 \mathrm{mmHg}$. There was a right-to-left shunt at atrial level. The right ventricular angiogram showed a filling defect in the right ventricular outflow tract stenosing the pulmonary valve and the pulmonary artery (Fig. 1). A second filling defect was seen in the right ventricular cavity causing some regurgitation into the right atrium.

At the age of 3 months this baby was operated upon using cardiopulmonary bypass. A right ventriculotomy revealed a large papilliform tumour rising from the ventricular septum, and extending into the tricuspid valve ring towards the atrial septum; the tumour was removed but not eradicated. After the closure of the ventricle the baby recovered uneventfully, but a few hours later developed convulsions; the blood pressure fell and in spite of an adrenaline drip, defibrillation, and resuscitation, she died.
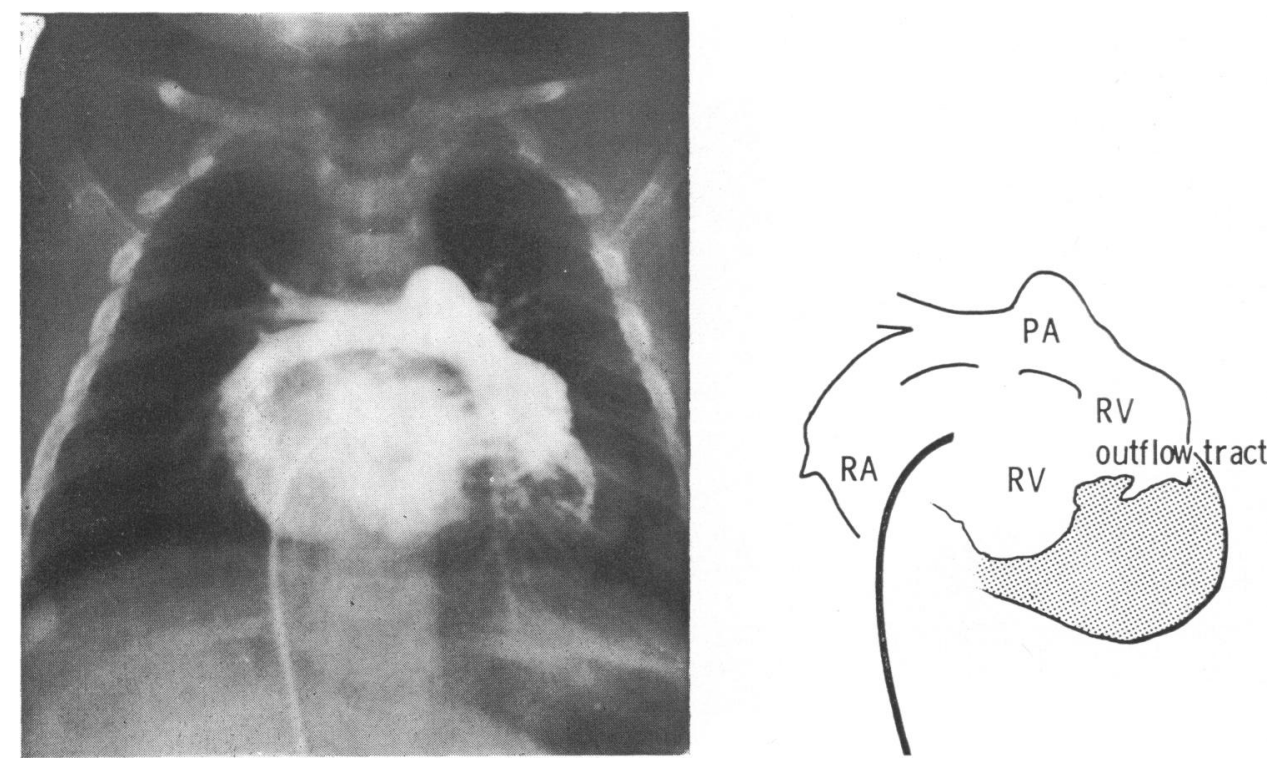

FIG. 1.-Case A4. Posteroanterior RV angiogram, showing large filling defect in the cavity of $R V$ obstruction to the RV outflow tract, and regurgitation through the tricuspid valve. 
Necropsy showed a heart tumour arising from the interventricular septum occluding the right ventricular outflow tract, protruding through the tricuspid valve into the right atrium. Histologically the tumour was a rhabdomyoma. No other tuberous sclerosis changes were found elsewhere.

B5: Male, 3 years. At the age of $2 \frac{1}{2}$ years this boy was admitted with a history of having had two episodes of falling without loss of consciousness, within a month. Four days before his admission he fell while walking and sustained a minor injury to his chest. After this he was noted to be cold and sweating and to have an increased heart rate. He was admitted to his local hospital where he was found to be in shock, and his ECG showed ventricular tachycardia. $\mathrm{He}$ was transferred to this hospital, a pale anxious child, not cyanosed but distressed. BP $60 / 50 \mathrm{mmHg}$, pulse rate greater than 250 a minute, the heart was clinically enlarged, the liver was $5 \mathrm{~cm}$ below the costal margin, there was no peripheral oedema. Chest $x$-ray showed cardiomegaly with lung atelectasis.

Three hours after admission he had cardiac arrest which failed to respond to external cardiac massage; thoracotomy was therefore performed, the heart was noted to be in ventricular fibrillation, and only after internal cardiac massage and DC defibrillation was sinus rhythm established. During the cardiac massage a tumour was felt at the right border of the heart, approximately $5 \mathrm{~cm}$ in diameter and hard in consistency. After this episode he was maintained on quinidine, and remained well apart from two episodes of chest pain. Two months later he was readmitted to hospital for cardiac catheterization. This time BP $115 / 70 \mathrm{mmHg}$ and a grade $2-3 / 6$ presystolic murmur was audible over the apex. The venous angiogram showed a filling defect in the tricuspid valve region, and the pulmonary artery was very large. Catheterization showed a left-to-right shunt at atrial level also.

On cardiopulmonary bypass a tumour was found in the right ventricular wall. The tricuspid valve was displaced by the tumour. The tumour was excised, but when the bypass was discontinued he did not maintain adequate cardiac output. In spite of all supportive efforts, including pacing, normal cardiac output was not achieved and the boy died.

The appearance and the histology of enucleated tumour was fibromatous.

B6: Male, 10 months. At 7 months of age this boy became breathless and a poor feeder. As he was found to have a large heart and signs of heart failure, he was referred for investigation. On admission he had a rapid respiratory rate, with slight costal recession, and scattered crepitations in the lungs. There was a grade $3 / 6$ pansystolic murmur audible over the left sternal edge,
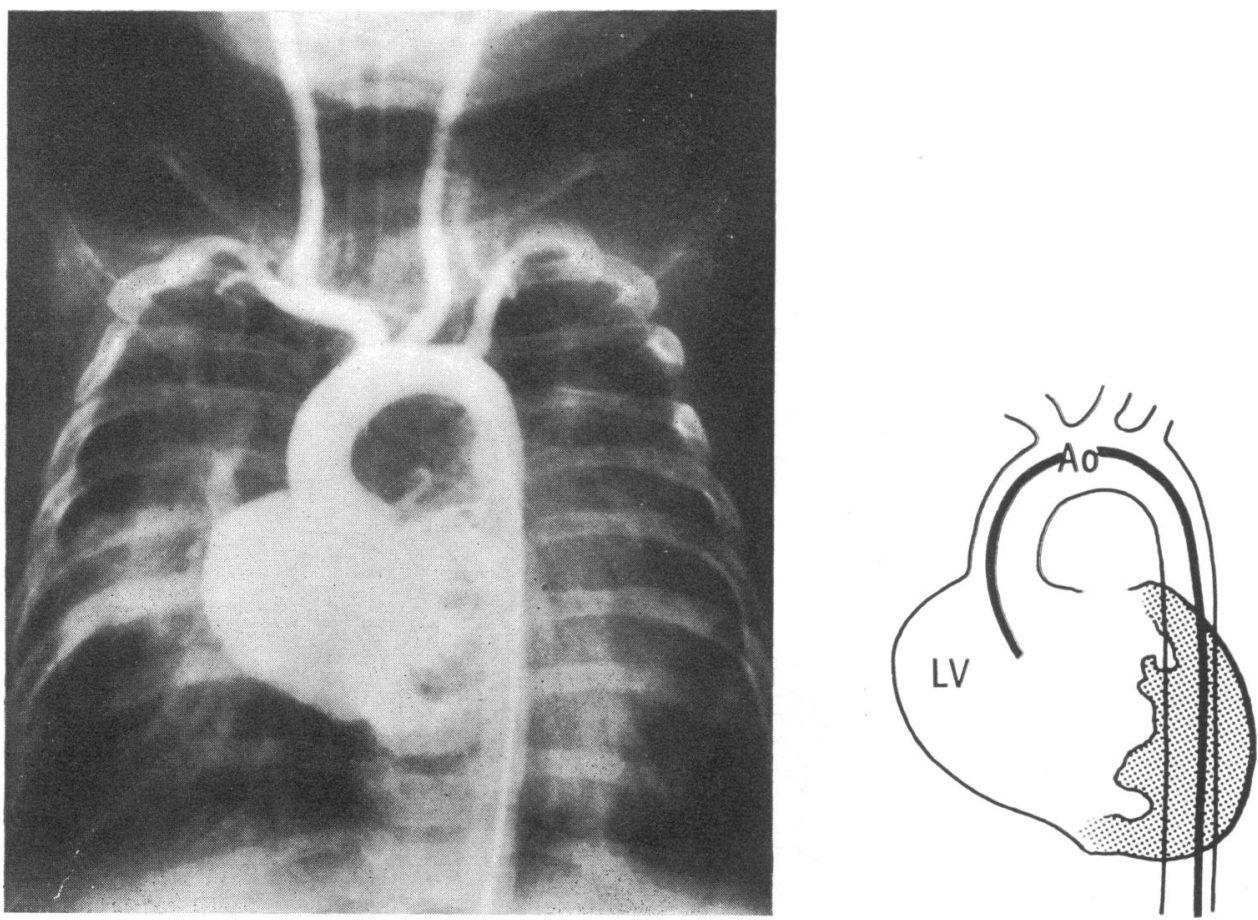

FIG. 2.-Case B6. Posteroanterior LV angiogram, showing large filling defect in the cavity of LV with considerable mitral incompetence. 


\section{Primary Cardiac Tumours in Childhood}

the liver was $4 \mathrm{~cm}$ below the costal margin. There was no peripheral oedema.

Chest $x$-ray showed a grossly enlarged heart, pulmonary vessels were within normal limits. ECG showed short PR-inverval, deep $Q$ waves and unusually tall $R$ in $V_{3-5}$. With the suggested diagnosis of an aberrant coronary artery he was investigated next day. No abnormal pressures were recorded. A left ventricular angiogram (Fig. 2) showed a gross filling defect in the left ventricular cavity with considerable mitral incompetence. Coronary angiography showed that the left coronary artery distribution was distorted by a mass in the wall of the left ventricle.

At operation a whitish tumour was seen protruding from the lateral aspect of the left ventricle. The mass was dissected out and the large coronary artery supplying the tumour had to be sacrificed. He came off bypass easily and was put on a ventilator. On the fourth postoperative day it was evident that he had developed a right hemiparesis.

$\mathrm{He}$ has a residual right spastic hemiparesis and is at present attending a handicapped children's day school.

The histology of the tumour showed an oval-shaped fibromatous tumour weighing $76 \mathrm{~g}$.

C7: Male, 4 months. This child had dyspnoea and poor feeding around the fourth month of his life, having had an indefinite history of cyanosis since birth.
On admission he was found to be pale with a respiratory rate of 80 per minute. An ejection systolic murmur was heard over the left sternal border. The liver was $3 \mathrm{~cm}$ below the costal margin. There was no peripheral oedema. ECG on admission showed right ventricular hypertrophy. Chest $x$-ray showed a large heart with normal lung markings. $\mathrm{He}$ was given digitalis and showed some improvement, but later he deteriorated and the ECG showed complete AV dissociation.

Cardiac catheterization showed a subvalvar gradient in the right ventricular outflow tract, and a right-to-left shunt at atrial level. Angiocardiography showed a filling defect in the body of the right ventricle causing an outflow obstruction. On cardiopulmonary bypass, the right ventricle was explored by Mr. E. Aberdeen and was found to be almost obliterated by a tumour; a dilator was passed from the pulmonary artery to the right ventricle and a Brock punch was used to remove some of the tumour that infiltrated the whole ventricle. After cardiopulmonary bypass had been stopped his condition steadily deteriorated and he died.

Necropsy. The right ventricle appeared abnormal and pale, the tricuspid valve orifice was abnormal, the medial cusp being pushed up and across the opening by a firm mass. The right ventricular cavity contained a massive tumour originating from the anterior aspect of the thickened myocardium and extending upwards to the outflow tract. Histologically it was a myxoma.
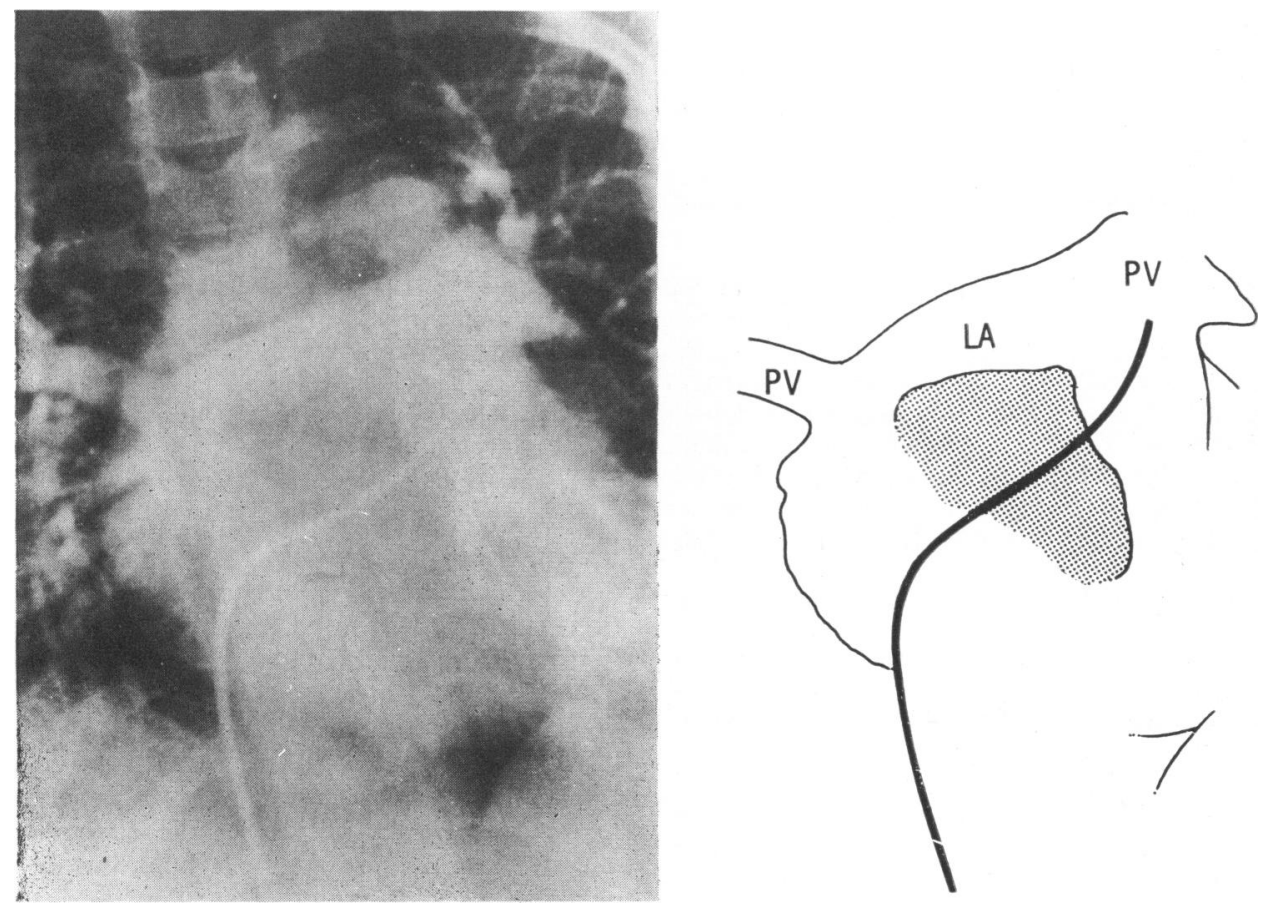

FIG. 3.-Case C8. Posteroanterior pulmonary artery angiogram showing recirculation to LA with a large filling defect in its cavity. 
Clinical and Pathological Da孪 in

\begin{tabular}{|c|c|c|c|c|c|c|}
\hline No. & $\begin{array}{l}\text { Age } \\
(\mathrm{yr})\end{array}$ & Sex & Site & Clinical Symptoms & Murmurs & $X$-ray \\
\hline \multicolumn{3}{|c|}{ A. RHABDOMYOMAS } & & & & \\
\hline 1 & $54 / 12$ & $\mathrm{~F}$ & $\mathrm{RV} / \mathrm{LV}$ & Epiloia, tuberous sclerosis, epilepsy & 一 & 一 \\
\hline 2 & 4 & $\mathrm{~F}$ & $\mathrm{RV} / \mathrm{LV}$ & $\begin{array}{l}\text { Epiloia, tuberous sclerosis, epilepsy } \\
\text { aminoaciduria, and glucosoria, } \\
\text { cardiac arrest }\end{array}$ & - & - \\
\hline 3 & 212 & $\mathbf{F}$ & RV & $\begin{array}{l}\text { Early cyanosis, slow feeding, } \\
\text { breathlessness }\end{array}$ & $\begin{array}{l}\text { Sys. murmur over PA } \\
\text { and LSE }\end{array}$ & $\begin{array}{l}\text { Enlarged heart, diminishe } \\
\text { vascularity }\end{array}$ \\
\hline 4 & 312 & $\mathrm{~F}$ & RV & Early cyanosis, good development & $\begin{array}{l}\text { Ejection sys. murmur over } \\
\text { PA; wide split } 2 \text { nd } \\
\text { sound }\end{array}$ & Very large heart \\
\hline \multicolumn{2}{|c|}{ B. FIBROMAS } & & & & & \\
\hline 5 & 3 & $\mathbf{M}$ & RV & $\begin{array}{l}\text { Ventricular tachycardia and shock } \\
\text { after chest trauma, leading to } \\
\text { cardiac arrest; tumour palpated } \\
\text { in rt ventricle during cardiac } \\
\text { massage }\end{array}$ & Presystolic murmur at apex & $\begin{array}{l}\text { Cardiomegaly with lung } \\
\text { atelectasis }\end{array}$ \\
\hline 6 & 1012 & $\mathrm{~F}$ & $\mathrm{LV}$ & $\begin{array}{l}\text { Poor feeder and breathless at age } \\
\text { of } 7 / 12\end{array}$ & $\begin{array}{l}\text { Pansystolic murmur over } \\
\text { LSE }\end{array}$ & $\begin{array}{l}\text { Grossly enlarged heart, } \mathrm{n} \\
\text { lung fields }\end{array}$ \\
\hline \multicolumn{2}{|c|}{ C. $M Y X O M A S$} & & & & & \\
\hline 7 & 412 & $\mathbf{M}$ & RV & $\begin{array}{l}\text { Indefinite cyanosis from birth, } \\
\text { dyspnoea and poor feeder later }\end{array}$ & $\begin{array}{l}\text { Ejection systolic murmur } \\
\text { over LSE }\end{array}$ & $\begin{array}{l}\text { Enlarged heart, normal lu } \\
\text { fields }\end{array}$ \\
\hline 8 & 7 & $\mathbf{M}$ & LA & $\begin{array}{l}\text { Joint pains, raised ERS, suspected } \\
\text { SBE, thromboembolic phenomena } \\
\text { including myocardial infarction }\end{array}$ & $\begin{array}{l}\text { Gallop rhythm, doubtful } \\
\text { mitral murmur }\end{array}$ & $\begin{array}{l}\text { Enlarged left atrium, dou } \\
\text { contour }\end{array}$ \\
\hline
\end{tabular}

C8: Male, 7 years. This 7 -year-old boy was admitted to another hospital because of joint pains, intermittent fever, and raised ESR. Because of a doubtful mitral murmur heard over the heart, ultrasound examination of the mitral valve was made, and this suggested a tumour lying behind the mitral valve. Arrangements were made to investigate the patient by angiocardiography, but before this was done he had a cardiac arrest with posterior cardiac infarction and embolism to the left arm and right leg. He was resuscitated, and angiocardiogram (Fig. 3) confirmed a lobulated tumour of the left atrium. He was referred to this hospital for operation. On arrival he was febrile, pale, and confused. Pulses were absent in the left arm and right leg. There was a gallop rhythm, but no thrills or murmurs were noted. Hb $8 \mathrm{~g} / 100 \mathrm{ml}$, ESR $47 \mathrm{~mm} / 1 \mathrm{hr}$.

Next day the child was explored using cardiopulmonary bypass. The left atrium was opened through a medial sternotomy, and a large myxoma was excised from its attachment to the right lateral wall of the atrium.

His postoperative course was uncomplicated and he was discharged home after three weeks.
The tumour was soft and polypoid, being composed of gelatinous tissue with focal haemorrhages that microscopically were myxoma.

The clinical and pathological findings of the 8 patients are summarized in the Table.

\section{Clinical Evaluation}

Evaluating cardiac tumours requires individual discussion of each type of tumour, as the manifestations vary considerably from case to case, depending in part upon the histological type of tumour but mainly upon its location (Edwards, 1968).

Intramural tumours may be silent or may give conduction aberrations because of infiltration of conduction tissue (James and Stanfield, 1955). Intracavitary tumours, by their space-occupying nature may be responsible for inflow or outflow obstruction. Murmurs of varying nature may be heard from time to time-a finding of considerable diagnostic value (Engle et al., 1962). Fragmenta- 
ildren with Primary Cardiac Tumours

\begin{tabular}{|c|c|c|c|}
\hline ECG & Cath./Angio. Findings & Pathological Findings & Course \\
\hline $\begin{array}{l}\text { trial paroxysmal } \\
\text { extrasystoles }\end{array}$ & - & $\begin{array}{l}\text { Diffused intramural tumours of } \\
\mathrm{RV} / \mathrm{LV} \text {, rhabdomyoma }\end{array}$ & Died during epileptic fit \\
\hline 一 & 一 & $\begin{array}{l}\text { Diffused intramural tumours of } \\
\text { RV/LV rhabdomyoma }\end{array}$ & Died during epileptic fit \\
\hline VH & $\begin{array}{l}\text { Raised RV pressure, filling defect } \\
\text { in RV obstructing RV outflow } \\
\text { 2nd defect arising from ventricular } \\
\text { septum }\end{array}$ & Rhabdomyoma arising from RV wall & Died during bypass \\
\hline $\begin{array}{l}\text { 'andering pacemaker } \\
\text { LBBB (WPW syndrome) }\end{array}$ & $\begin{array}{l}\text { Raised RV pressure, PA not } \\
\text { entered, } 2 \text { filling defects in RV } \\
\text { pushing pulmonary valve and } \\
\text { tricuspid valve }\end{array}$ & $\begin{array}{l}\text { Rhabdomyoma arising from septum } \\
\text { occluding RV outflow tract and } \\
\text { protruding through to valve }\end{array}$ & $\begin{array}{l}\text { Tumour removed but not eradicated } \\
\text { few hours after bypass developed } \\
\text { convulsions and died }\end{array}$ \\
\hline entricular tachycardia & $\begin{array}{l}\text { Filling defect in tricuspid valve } \\
\text { area; enlarged pulmonary artery }\end{array}$ & $\begin{array}{l}\text { Fibroma originating from RV wall } \\
\text { extending towards RA }\end{array}$ & $\begin{array}{l}\text { Did not come off bypass; could not } \\
\text { maintain adequate blood pressure }\end{array}$ \\
\hline $\begin{array}{l}\text { 1ort } P R \text { interval, deep } Q \\
\text { waves } V_{3-5} \text { and tall } R \\
\text { waves } V_{3-5}\end{array}$ & $\begin{array}{l}\text { Gross filling defect in LV cavity, } \\
\text { considerable mitral incompetence; } \\
\text { Lt coronary artery distorted by } \\
\text { mass in wall of lt ventricle }\end{array}$ & $\begin{array}{l}\text { Oval tumour fibromatous in origin, } \\
\text { removed from } \mathrm{LV}\end{array}$ & $\begin{array}{l}\text { Tumour dissected from LV; Lt } \\
\text { coronary artery sacrificed; } \\
\text { developed rt hemiparesis, } \\
\text { remained with spastic hemiparesis; } \\
\text { attends handicapped childrens' } \\
\text { school }\end{array}$ \\
\hline $\mathrm{VH}, \mathrm{AV}$ dissociation & $\begin{array}{l}\text { Subvalvar gradient in RV outflow } \\
\text { tract, filling defect in RV outflow } \\
\text { tract }\end{array}$ & $\begin{array}{l}\text { Massive tumour myxomatous in } \\
\text { origin, emerging from RV wall } \\
\text { extending to outflow tract and } \\
\text { tricuspid valve }\end{array}$ & $\begin{array}{l}\text { Tumour punched by Brock puncher, } \\
\text { patient did not come off bypass }\end{array}$ \\
\hline sterior wall infarction & Filling defect of left atrium & $\begin{array}{c}\text { Soft polypoid tumour removed from } \\
\text { left atrium, myxomatous in origin }\end{array}$ & $\begin{array}{l}\text { Tumour successfully removed on } \\
\text { bypass with uncomplicated postop. } \\
\text { course }\end{array}$ \\
\hline
\end{tabular}

tion of the intracavitary tumour can lead to embolism, which may be the presenting feature (Sanyal et al., 1967).

Incidence. Though the incidence of heart tumours in this series is within the range reported by the others (Gasul et al., 1966), the point should be made that during the first 10 years of this survey only one case of heart tumour was diagnosed, and this was found at the necropsy of a girl with tuberous sclerosis. The remaining 7 cases were diagnosed during the past 10 years, reflect improvement in diagnostic tools, and awareness of the condition.

Familial history. Familial incidence is well substantiated in tuberous sclerosis but not in other primary heart tumours (Lagos and Gomez, 1967); 3 of our patients were proven cases of rhabdomyoma in patients with tuberous sclerosis, and the fourth had a rhabdomyoma of the heart only, but none of these had a family history. It is interesting to note that in patient A2, two members of her family (father and twin sister) suffered from renal pathology similar to that of the patient. However, we know of no previous report linking tuberous sclerosis of the kidney and amminoaciduria.

Age. As might be expected, the obstructive type tumours presented with clinical manifestations early in life. Three patients with right ventricular outflow tract obstruction were diagnosed and operated upon under the age of 4 months, while the left atrial myxoma presented at 7 years.

Clinical manifestations. Two patients with the intramural tumours did not manifest cardiac symptoms, and as they grew to childhood the effect of the associated tuberous sclerosis dominated the clinical picture. In the other 2 patients with intracavity rhabdomyomas, cyanosis was present almost from birth and so were the auscultatory findings of pulmonary stenosis. Both were without 
clinical symptoms of tuberous sclerosis, and only one showed changes in his brain at necropsy. Patient B5 is most interesting as he is the only case to our knowledge where the tumour was diagnosed by palpation. Later when the tumour invaginated into his right atrium, he had auscultatory findings of tricuspid incompetence. The other right ventricular tumour (patient $\mathrm{C7}$ ) developed symptoms from birth, breathlessness, dyspnoea, enlarged heart, with an ejection systolic murmur heard over the left sternal edge.

The child with the left ventricular tumour (patient B6) became breathless only at 7 months, showed signs of heart failure, and had a pansystolic murmur. The child with the left atrial myxoma presented with the classical findings of this condition.

Chest X-ray. The radiological appearance of the heart in patients with intracardiac tumours is by no means specific and in some instances the heart shadow appeared normal (Steiner, 1968). This was so in all the intramural tumours. The ventricular intracavitary tumours had large hearts. Patient A3, where the obstruction to his outflow tract was severe, showed underfilled lung fields as well, and patient $\mathrm{C} 8$ showed an enlarged left atrium.

ECG. It is doubtful whether the paroxysmal atrial extrasystoles in patient Al were caused by his tumour, as the tumours were found in the ventricles only. Among the patients with the right ventricular tumours, patient A3 showed right ventricular hypertrophy and the 3 others had aberrations of conduction. The first presented with ventricular tachycardia, the second with an ECG similar to that of Wolff-Parkinson-White syndrome, and the third developed AV dissociation.

The left ventricular fibroma gave a picture that was suggestive of an aberrant left coronary artery. The left atrial myxoma had a tracing suggesting a posterior myocardial infarction.

Angiocardiography and cardiac catheterization. Though cardiac catheterization in this situation may give rise to complications such as conduction aberrations or tumour emboli, this was not our experience. All the filling defects were nicely shown on the angiograms, as was the distortion of the coronary arteries due to intramural tumour. Pressure gradients and abnormally high pressures due to outflow obstruction were quite easily detected.

\section{Conclusions}

Primary cardiac tumours may present at birth or in early infancy, and the clinician should be aware of this possibility.
The diagnosis may be suspected on clinical grounds substantiated by radiology, ECG, and cardiac catheterization, but the definitive diagnosis is usually made on angiocardiography. Though physiological investigations of cardiac tumours might run potential risk, this procedure may be performed successfully by a skilled cardiologist.

Surgery may be a life-saving measure in tumours with outflow tract obstruction, and they should be operated upon as soon as the diagnosis is established. The main object of surgery should be to free the outflow tract obstruction, and not to insist on complete eradication of the tumour.

Patient $A_{t}$ was referred to us from the Royal Aberdeen Hospital, and patient $\mathrm{C}_{8}$ from the Central Middlesex Hospital, London. We are grateful to Dr. R. E. Bonham-Carter, for advice.

\section{REFERENCES}

Catton, R. W., Guntheroth, W. G., and Reichenbach, D. D. (1963) A myxoma of the pulmonary valve causing severe stenosis in infancy. American Heart fournal, 66, 248.

Edlund, S., and Holmdahl, K. (1957). Primary tumour of the heart. Acta Paediatrica, 46, 59.

Edwards, J. E. (1968). Heart Disease in Infants, Children and Adolescents, p. 1072. Ed. by A. J. Moss and F. H. Adams. Williams and Wilkins, Baltimore.

Engle, M. A., Ito, T., Ehlers, K. H., and Goldberg, H. P. (1962) Rhabdomyomatosis of the heart: diagnosis during life with clinical and pathologic findings. Circulation, 26, 712.

Fine, G. (1968). Neoplasms of the pericardium and heart. In Pathology of the Heart and Blood Vessels, 3rd ed., p. 851. Ed. by S. E. Gould. C. Thomas, Springfield, Illinois.

Gasul, B. M., Arcilla, R. A., and Lev, M. (1966). Heart Disease in Children: Diagnosis and Treatment, p. 1086. Lippincot:, Philadelphia; Pitman, London.

Gerbode, F., Kerth, W. J., and Hill, J. D. (1967). Surgical management of tumors of the heart. Surgery, 61, 94.

James, U., and Stanfield, M. H. (1955). A case of fibroma of the left ventricle in a child of 4 years. Archives of Disease in Childhood, 30, 187

Keith, J. D., Rowe, R. D., and Vlad, P. (1967). Heart Disease in Infancy and Childhood, 2nd ed., p. 1171. Macmillan, New York; Collier-Macmillan, London.

Lagos, J. C., and Gomez, M. R. (1967). Tuberous sclerosis reappraisal of a clinical entity. Mayo Clinic Proceedings, 42, 26.

Lincoln, J. C. R., Tynan, M. J., and Waterston, D. J. (1968). Successful excision of an endocardial fibroma of the left ventricle in a 10-month-old infant. Fournal of Thoracic and Cardiovascular Surgery, 56, 63.

Nadas, A. S., and Ellison, C. R. (1968). Cardiac tumors in infancy. American fournal of Cardiology, 21, 363.

Prichard, R. W. (1951). Tumors of the heart. Review of the subject and report of one hundred and fifty cases. Archives of Pathology, 51, 98.

Sanyal, S. K., De Leuchtenberg, N., Rojas, R. H., Stansel, H. C., and Browne, M. J. (1967). Right atrial myxoma in infancy and childhood. American fournal of Cardiology, 20, 263.

Steiner, R. E. (1968). Radiologic aspects of cardiac tumors. American fournal of Cardiology, 21, 344.

Van der Hauwaert, L. G. (1968). Paediatric Cardiology, p. 773. Ed. by Hamish Watson. Lloyd-Luke, London.

Wood, P. (1968). Diseases of the Heart and Circulation, 3rd ed., p. 735. Eyre and Spottiswoode, London.

Correspondence to Dr. R. E. Bonham-Carter, The Hospital for Sick Children, Great Ormond Street, London, WCIN 3JN. 